\title{
Stress-induced cardiovascular responses to cold pressortest in healthy young subjects
}

\author{
Valeri Nikolov *, Department of Nursing, Medical Faculty, Trakia University, Stara Zagora, Bulgaria \\ Miroslava Petkova, Department of Nursing, Medical Faculty, Trakia University, Stara Zagora, Bulgaria \\ Emil Nikolov, Department of Nursing, Medical Faculty, Trakia University, Stara Zagora, Bulgaria
}

\section{Suggested Citation:}

Nikolov, V., Petkova, M. \& Nikolov, E. (2020). Stress-induced cardiovascular responses to cold pressor test in healthy young subjects. Global Journal of Psychology Research: New Trends and Issues. 10(2), 89-95. https://doi.org/10.18844/gipr.v10i2.5308

Received April 22, 2020; revised June 20, 2020; accepted September 10, 2020.

Selection and peer review under responsibility of Prof. Dr. Tulay Bozkurt, Istanbul Kultur University, Turkey.

${ }^{0} 2020$ Birlesik Dunya Yenilik Arastirma ve Yayincilik Merkezi. All rights reserved.

\begin{abstract}
Hypertension is one of the leading diseases of the cardiovascular system. It is manifested by changes in arterial stiffness. Cardiovascular reactivity, especially blood pressure (BP), changes during the cold pressor test (CPT) depending on various factors. Undoubtedly, stress is one of the most important factors. The aim of this study is to investigate the various effects of CPT on cardiovascular responses in healthy young subjects. A total of 56 healthy individuals aged between 21 and 26 years were investigated. The cardiovascular responses (BP, heart rate and aortic pulse wave velocity) to CPT were recorded by using the applanation tonometry. The Medical Outcomes Study Sleep Scale and the State-Trait Anxiety Inventory were used. $32.14 \%(n=18)$ of the individuals who showed differences in systolic BP more than $22 \mathrm{~mm} \mathrm{Hg}$ and differences in diastolic BP more than $18 \mathrm{~mm} \mathrm{Hg}$ after the CPT were defined as hyperreactors. Hyperreactors showed a significantly higher increase in sleep disturbances $(p>0.01)$ and anxiety when compared to normoreactors. The CPT used to diagnose cardiovascular reactivity in young individuals and the assessment of perceived stress can help identify candidates who are at risk of hypertonic disease in the future.
\end{abstract}

Keywords: Cold pressor test, cardiovascular reactivity, applanation tonometry, blood pressure, stress.

\footnotetext{
* ADDRESS FOR CORRESPONDENCE: Valeri Nikolov, Department of Nursing, Medical Faculty, Trakia University, Stara Zagora,
} Bulgaria. E-mail address: vtsnikolov@gmail.com 


\section{Introduction}

More than 80 years ago, Hines and Brown (1936) suggested that vascular hyper reactivity, manifested by the cold pressor test (CPT), was a potential predictor of hypertension (Wood, Sheps, Elveback \& Schirger, 1984). Menkes et al. (1989) noted that cardiovascular reactivity to stress was hypothesised to be a marker for subsequent neurogenic hypertension. Many investigators indicate that the intensity of cold and pain stress is involved in the blood pressure (BP) response to CPT (Kregel, Seals \& Callister, 1992; Moriyama \& Ifuku, 2010).

Cardiovascular reactivity, especially BP, changes during the CPT depending on various factors. The pressor response to CPT is induced by the enhanced sympathetic nerve activity and by the increased cardiac output during the initial period (Ifuku, 2015; Yamamoto, Iwase \& Mano, 1992). Undoubtedly, psychological stress is one of the most important factors (Cuevas, Williams \& Albert, 2017; SanchezGonzalez, May, Brown, Koutnik \& Fincham, 2013).

Sleep duration and sleep complaints can have predictive power in relation to cardio metabolic health outcomes (Grandner, Jackson, Pak \& Gehrman, 2012). Most of the authors consider that pulse wave velocity (PWV) is the essential way to evaluate, non-invasively, arterial stiffness. Some authors conclude that high PWV values are associated with increased arterial stiffness and increased risk for cardiovascular disease (Doupis, Papanas, Cohen, McFarlan \& Horton, 2016). However, the subjective sleep duration is variably associated with arterial stiffness, differing from studies, and the evidence of the relationship between sleep duration and cardiovascular risks for women was weaker and less conclusive than men (Aziz et al., 2017).

Sleep and its adequacy and quality are important aspects in the process of maintaining optimal health and well-being (Mullan, 2014).Stress and sleep have a significant correlation. Many psychological and social factors, such as emotional stress, anxiety, depressive mood, financial hardship, smoking and alcohol consumption, affect sleep (Nunes da Silva, Martins, Waquim \& Lopes, 2012). Sleep quality has been linked to a number of diseases, such as cardiovascular problems (Kashani, Eliasson \& Vernalis, 2012). The relationship between sleep duration and sleep quality with arterial stiffness is also shown (Tsai, Wu, Yang, Huang \& Chang, 2014).PWV is now scientifically proven to be the most accurate way to assess non-invasive arterial stiffness (Doupis et al., 2016). The aim of the study is to investigate the various effects of CPT on cardiovascular responses in healthy young subjects.

\section{Methods}

\subsection{Subjects}

Fifty-six healthy individuals aged between 21 and 26 years were investigated. The participants were non-smokers for at least 6 months prior to the investigation. The participants were non-hypertensive individuals (exclusion criteria for this group were BP $>140 / 90 \mathrm{mmHg}$ ). People taking antihypertensive medications or other medications known to affect BP (e.g., $\beta$-blockers, thyroid, hormones or steroids) were excluded from the study. Participants with known cardiac conditions (e.g., heart failure, coronary artery disease or myocardial infarction), known vascular conditions (e.g., peripheral vascular diseases) and those who were taking medications for a psychiatric disorder (e.g., schizophrenia or major depressive disorder) that may affect psychological measures were also excluded. The study was conducted in Star a Zagora during the period February -June 2019. Before the CPT, participants completed a questionnaire containing information on socio-demographic data and psychological scales. Before entering the study, all participants provided written informed consent, and the study was conducted according to the principles of the Declaration of Helsinki (World Medical Association, 2001). 


\section{2. $C P T$}

All participants underwent the CPT according to Hines and Brown (1936). The right hand was immersed up to the wrist in ice cold water $\left(4^{\circ} \pm 0.5^{\circ} \mathrm{C}\right)$ for 2 minutes (Figure1).

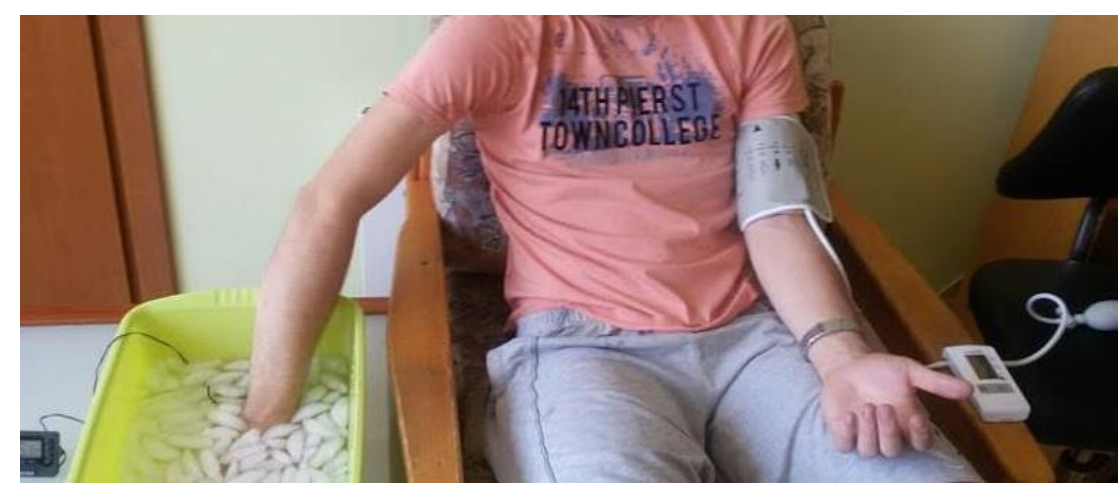

Figure 1. CPT

Immediately before and after the period of ice water immersion, the cardiovascular responses [BP, heart rate (HR), aortic PWV] to CPT were recorded by using the applanation tonometry. The difference between peak and basal BPs determined the level of vascular reactivity. Subjects were then classified according to their response to the CPT. Subjects who responded to the CPT with an increase in BP of at least $25 \mathrm{~mm} \mathrm{Hg}$ systolic or $20 \mathrm{~mm} \mathrm{Hg}$ diastolic were designated as hyperreactors and subjects with a lesser increase than that were designated as normoreactors (Menkes et al., 1989; Wood et al., 1984).

\subsection{Applanation tonometry}

The cardiovascular responses (BP, HR, aortic PWV) to CPT were recorded by using the applanation tonometry. The PWV measurements were carried out using a SphygmoCor apparatus (SphygmoCor system, AtCor Medical, Sydney, Australia) after a 10-minute rest (supine position) (Laurent et al., 2006; Townsend et al., 2015). To minimise the effect of the circadian cycle, measurements were taken at approximately the same time in the morning on an empty stomach after instructions to refrain from any beverages of caffeine, ethanol and smoking at least 12 hours prior to the estimates (Papaioannou et al., 2006).

PWV was registered between the carotid and femoral artery in the supine position. The SphygmoCor probe over the carotid and femoral artery was used for non-invasive pulse measurements (Qureshi et al., 2007).The values of the distance from the carotid to femoral artery, measured directly between artery location and the supra-sternal notch were entered into the SphygmoCor software database. PWV was automatically calculated using AtCor software (Figure 2).

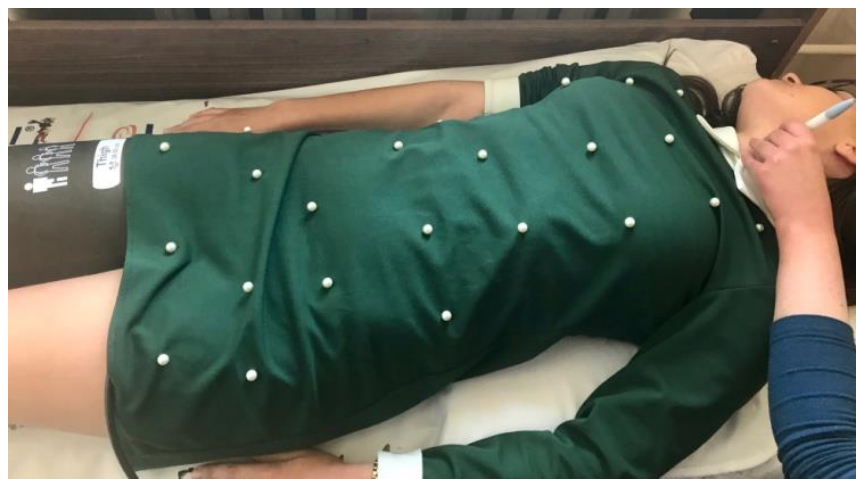

Figure 2. Applanation tonometry 


\subsection{Psychological questionnaires}

\subsubsection{Medical outcomes study sleep scale (MOS-SS)}

The MOS-SS includes 12 items assessing sleep disturbance, sleep adequacy, somnolence, quantity of sleep, snoring and awakening with shortness of breath or with a headache (Stewart \& Ware, 1992). A sleep problem indexes grouping items from each of the former domains.

\subsubsection{State-Trait Anxiety Inventory (STAI)}

Anxiety was measured by Spielberger's STAI. The 40-item 4-point Likert scale was developed to measure anxiety in adults. The first subscale measures state anxiety and the second subscales measures trait anxiety (Spielberger, Gorsuch, Lushene, Vagg \& Jacobs, 1983). Total scores obtained from the subscales ranged from 20 to 80, with higher scores indicating greater anxiety. In this study, the internal consistency of the STAI was very good; Cronbach's $\alpha$ was 0.89 for state anxiety and 0.87 for trait anxiety.

\section{Results and discussion}

The individuals who showed differences in systolic BP more than $22 \mathrm{~mm} \mathrm{Hg}$ and differences in diastolic BP more than $18 \mathrm{~mm} \mathrm{Hg}$ after the CPT were defined as hyperreactors (Table 1).

Table 1. Comparison of values of $B P$ in norm reactors and hyperreactors

\begin{tabular}{|c|c|c|c|c|}
\hline Values (mm Hg) & Normoreactors & $\begin{array}{c}\text { Mean } \pm \text { SD } \\
\text { Hyperreactors }\end{array}$ & $t$ value & $P$ value \\
\hline $\mathrm{SBP}_{1}$ & $113.33 \pm 6.12$ & $119.23 \pm 8.64$ & 3.18 & 0.01 \\
\hline $\mathrm{DBP}_{1}$ & $77.15 \pm 7.44$ & $79.26 \pm 11.76$ & 2.45 & 0.01 \\
\hline $\mathrm{SBP}_{2}$ & $125.14 \pm 10.16$ & $146.65 \pm 8.83$ & 9.54 & $<0.001$ \\
\hline $\mathrm{DBP}_{2}$ & $86.09 \pm 8.14$ & $99.38 \pm 6.26$ & 4.32 & 0.01 \\
\hline Difference of SBP & $13.35 \pm 2.23$ & $25.83 \pm 7.19$ & 6.24 & $<0.001$ \\
\hline Difference of DBP & $8.92 \pm 4.38$ & $21.13 \pm 6.78$ & 10.38 & $<0.001$ \\
\hline
\end{tabular}

$\mathrm{SBP}_{1}=$ Initial systolic blood pressure; $\mathrm{DBP}_{1}=$ Initial blood pressure after immersion blood pressure; $\mathrm{SBP}_{2}=$ Systolic blood pressure after immersion; $\mathrm{DBP}_{2}=$ Diastolic blood pressure after immersion; $\mathrm{SD}=$ Standard deviation.

For the present study, the distribution between the two groups (normoreactors and hyperreactors) was $67.9 \%(n=38)$ normoreactors, respectively, and 32.1\% $(n=18)$ hyperreactors (Table 2). Previous studies of children and young people shared similar data. Hines and Brown (1936) established 10\% of hyperreactors in children (7-17 years), Moriyama and Ifuku (2007) established 29\% and Ifuku (2015) established $35.3 \%$ in young people (18-24 years).

Table 2. Percentage of normoreactors and hyperreactors among the studied subjects

\begin{tabular}{lcc}
\multicolumn{1}{c}{ Groups } & Number of individuals & $\%$ \\
\hline Normoreactors & 38 & 67.9 \\
Hyperreactors & 18 & 18 \\
\hline
\end{tabular}

After the deviation from the standard values, which we observed in hyperreactors, we established larger increases of the HR. In both normoreactors and hyperreactors, the HR during cold stress increased significantly (Table 3). Similar results have been found by other authors (Ifuku, 2015). The results of the stroke volume did not differ with respect to the two groups. 
Table 3. Comparison on values of HR (beats/minute) in normoreactors and hyperreactors

\begin{tabular}{lcc}
\hline \multicolumn{1}{c}{ Groups } & HR $_{\mathbf{1}}$ & $\mathbf{H R}_{\mathbf{2}}$ \\
\hline Normoreactors & $64.7 \pm 9.2$ & $66.6 \pm 7.8^{*}$ \\
Hyperreactors & $67.2 \pm 8.5$ & $78.7 \pm 10.4^{* *}$ \\
\hline
\end{tabular}

Data are mean $\pm \mathrm{SD}$. $\mathrm{HR}_{1}$ : Initial heart rate, $\mathrm{HR}_{2}$ : Heart rate after immersion. Significantly different: ${ }^{*} p<0.05 ;{ }^{* *} p<0.01$, respectively.

In terms of arterial stiffness, the aortic PWV increase during coldwater immersion is greater in hyperreactors than normoreactors. This response to PWV in hyperreactors may be due to a greater increase in arterial stiffness caused by increased BP, which is manifested at increased HR (Laurent et al., 2003; Moriyama \& Ifuku, 2007).

Significant variations in sleep disturbance were distinguished during the analysis of sleep problems between hyperreactors and normoreactors, although the rest of the factors also tended to have higher values among hyperreactors (Table 4). The results were similar during the anxiety tests among the subjects.

Table 4. Comparing levels of sleep problems between normoreactors and hyperreactors

\begin{tabular}{lcccccc}
\hline \multicolumn{1}{c}{ Groups } & Number & Sleep disturbance & Somnolence & Sleep adequacy & Snoring & Sleep quantity \\
\hline Normoreactors & 38 & 4.76 & 7.12 & 2.73 & 2.54 & 6.17 \\
Hyperreactors & 18 & 10.30 & 8.53 & 3.67 & 3.15 & 7.97 \\
T & & -8.14 & -1.82 & -0.97 & -1.42 & 1.86 \\
Sig & & 0.0001 & 0.52 & 0.43 & 0.08 & 0.06 \\
\hline
\end{tabular}

The levels of anxiety in hyperreactors are higher in comparison to normoreactors. These elevated levels of anxiety and sleep disturbances in hyperreactors lead us to believe that they are at the root of increased cardiovascular reactivity, mainly due to changes in HR, most likely due to increased sympathetic activation, which is confirmed by the opinion of other authors (Grassi et al., 1998; Laurent et al., 2003; Moriyama \& Ifuku, 2007).

The increase in BP during immersion in cold water is a specific response to the cardiac function of the CPT in hyperreactors and depends on HR rather than cardiac contractility, and these findings suggest that the increased activity of the sympathetic lobe of the autonomic nerve leads to increased HR (Laurent et al., 2003). In this study, this is established against the background of increased levels of psychological stress provoked by sleep disorders and increased anxiety in hyperreactors. These results also confirm the opinion of Grassi et al. (1998) that HR differences are a reflection of differences in the sympathetic tone, particularly when differences in sympathetic tone are inferred from HR changes between different subjects rather than within the same subject.

\section{Conclusion}

The increase in BP during immersion in cold water is a specific response to the cardiac function of the CPT in hyperreactors and suggests an increased activity of the sympathetic lobe of the autonomic nervous system.

Higher levels of stress (measured as state anxiety) in healthy young people, identified as hyperreactors, in this study show elevated sympathetic activity and are a signal of their increased cardiovascular reactivity during the CPT.

CPT can be useful for diagnosing cardiovascular reactivity in young individuals, and evaluating anxiety and sleep quality can help identify candidates for a future risk of hypertension. 


\section{Acknowledgement}

This study was supported by Grant 8/2018 from the Medical Faculty, Trakia University, Stara Zagora, Bulgaria.

\section{References}

Aziz, M., Ali, S. S., Das, S., Younus, A., Malik, R., Latif, M. A.... Elizondo, J. V. (2017). Association of subjective and objective sleep duration as well as sleep quality with non-invasive markers of sub-clinical cardiovascular disease (CVD): a systematic review. Journal of Atherosclerosis and Thrombosis, 24(3), 208-226. doi:10.5551/jat.36194

Cuevas, A. G., Williams, D. R. \& Albert, M. A. (2017). Psychosocial factors and hypertension: are view of the literature. Cardiology Clinics, 35(2), 223-230. doi:10.1016/j.ccl.2016.12.004

Doupis, J., Papanas, N., Cohen, A., McFarlan, L. \& Horton, E. (2016). Pulse wave analysis by applanation tonometry for the measurement of arterial stiffness. The Open Cardiovascular Medicine Journal, 10, 188.doi:10.2174/1874192401610010188

Eich, R. H. \& Jacobsen, E. C. (1967). Vascular reactivity in medical students followed for $10 \mathrm{yr}$. Journal of Chronic Diseases, 20(8), 583-592.

Grandner, M. A., Jackson, N. J., Pak, V. M. \& Gehrman, P. R. (2012). Sleep disturbance is associated with cardiovascular and metabolic disorders. Journal of Sleep Research, 21(4), 427-433. doi:10.1111/j.13652869.2011.00990.x

Grassi, G., Vailati, S., Bertinieri, G., Seravalle, G., Stella, M. L., Dell’Oro, R. \& Mancia, G. (1998). Heart rate as marker of sympathetic activity. Journal of Hypertension, 16(11), 1635-1639.

Harlan Jr, W. R., Osborne, R. K. \& Graybiel, A. (1964). Prognostic value of the cold pressor test and the basal blood pressure: based on an eighteen-year follow-up study. The American Journal of Cardiology, 13(5), 683-687.

Hines Jr, E. A. \& Brown, G. E. (1936). The cold pressor test for measuring the reactibility of the blood pressure: data concerning 571 normal and hypertensive subjects. American Heart Journal, 11(1), 1-9.

Ifuku, H. (2015). Cardiovascular responses of blood pressure hyperreactors to the cold pressor test and exercise. The Journal of Physical Fitness and Sports Medicine, 4(4), 331-335.doi:10.7600/jpfsm.4.331

Ifuku, H., Moriyama, K., Arai, K. \& Shiraishi-Hichiwa, Y. (2007). Regulation of cardiac function during a cold pressor test in athletes and untrained subjects. European Journal of Applied Physiology, 101(1), 75-79. doi:10.1007/s00421-007-0475-y

Kashani, M., Eliasson, A. \& Vernalis, M. (2012). Perceived stress correlates with disturbed sleep: a link connecting stress and cardiovascular disease.Stress, 15(1), 45-51.doi:10.3109/10253890.2011.578266

Kregel, K. C., Seals, D. R. \& Callister, R. O. B. I. N. (1992). Sympathetic nervous system activity during skin cooling in humans: relationship to stimulus intensity and pain sensation. The Journal of Physiology, 454(1), 359-371. doi:10.1113/jphysiol.1992.sp019268

Laurent, P., Albaladejo, P., Blacher, J., Rudnichi, A., Smulyan, H. \& Safar, M. E. (2003). Heart rate and pulse pressure amplification in hypertensive subjects.American Journal of Hypertension, 16(5), 363-370. doi:10.1016/S0895-7061(03)00063-3

Laurent, S., Cockcroft, J., Van Bortel, L., Boutouyrie, P., Giannattasio, C., Hayoz, D....Struijker-Boudier, H. (2006). Expert consensus document on arterial stiffness: methodological issues and clinical applications. European Heart Journal, 27(21), 2588-2605. doi:10.1093/eurheartj/ehl254

Menkes, M. S., Matthews, K. A., Krantz, D. S., Lundberg, U., Mead, L. A., Qaqish, B., ... Pearson, T. A. (1989). Cardiovascular reactivity to the cold pressor test as a predictor of hypertension. Hypertension, 14(5), 524-530. doi:10.1161/01.HYP.14.5.524

Moriyama, K. \& Ifuku, H. (2007). Assessment of cardiac contractility during a cold pressor test by using (dP/dt)/P of carotid artery pulses. European Journal of Applied Physiology, 100(2), 185-191. doi:10.1007/s00421007-0415-x 
Moriyama, K. \& Ifuku, H. (2010). Increased cardiovascular reactivity to the cold pressor test is not associated with increased reactivity to isometric handgrip exercise. European Journal of Applied Physiology, 108(4), 837-843.

Mullan, B. A. (2014) Sleep, stress and health: a commentary. Stress Health, 30, 433-435. doi:10.1002/smi.2605

Nunes da Silva, J. M., Martins Costa, A. C., Waquim Machado, W. \& Lopes Xavier, C. (2012). Avaliacao da qualidade de sono em idosos nao institucionalizados. Conscientiae Saude, 11(1), 29-36. doi:10.5585/conssaude.v11n1.2940

Papaioannou, T. G., Karatzis, E. N., Papamichael, C. M., Karatzi, K. N., Zakopoulos, N. A., Lekakis, J. P., ... Stefanadis, C. (2006). Circadian variation of arterial pressure wave reflections. American Journal of Hypertension, 19(3), 259-263.doi:10.1016/j.amjhyper

Qureshi, G., Brown, R., Salciccioli, L., Qureshi, M., Rizvi, S., Farhan, S. \& Lazar, J. (2007). Relationship between aortic atherosclerosis and non-invasive measures of arterial stiffness. Atherosclerosis, 195(2), e190-e194. doi:10.1016/j.atherosclerosis.2007.06.021

Sanchez-Gonzalez, M. A., May, R. W., Brown, P. C., Koutnik, A. P. \& Fincham, F. D. (2013). Depressive symptoms contribute to increased wave reflection during cold pressor test in young adult men. American Journal of Hypertension, 26(6), 778-783. doi:10.1093/ajh/hpt012

Spielberger, C. D., Gorsuch, R. L., Lushene, R. E., Vagg, R. \& Jacobs, G. A. (1983). State-trait anxiety inventory. Self-evaluation questionnaire (form Y). Palo Alto, CA: Manual for the State-Trait Anxiety Inventory.

Stewart, A. L. \& Ware, J. E. (1992). Measuring functioning and well-being: the medical outcomes study approach. Durham, NC: Duke University Press.

Thacker, E. A. (1940). A comparative study of normal and abnormal blood pressures among university students, including the cold-pressor test. American Heart Journal, 20(1), 89-97.

Townsend, R. R., Wilkinson, I. B., Schiffrin, E. L., Avolio, A. P., Chirinos, J. A., Cockcroft, J. R., ... Najjar, S. S. (2015). Recommendations for improving and standardizing vascular research on arterial stiffness: a scientific statement from the American Heart Association. Hypertension, 66(3), 698-722. doi:10.1161/ HYP.00000000000000033

Tsai, T. C., Wu, J. S., Yang, Y. C., Huang, Y. H., Lu, F. H.\& Chang, C. J. (2014). Long sleep duration associated with a higher risk of increased arterial stiffness in males.Sleep, 37(8), 1315-20.doi:10.5665/sleep.3920

Wood, D. L., Sheps, S. G., Elveback, L. R. \& Schirger, A. (1984). Cold pressor test as a predictor of hypertension. Hypertension, 6(3), 301-6.

World Medical Association. (2001). World Medical Association Declaration of Helsinki. Ethical principles for medical research involving human subjects. Bulletin of the World Health Organization, 79(4), 373.

Yamamoto, K., Iwase, S. \& Mano, T. (1992). Responses of muscle sympathetic nerve activity and cardiac output to the cold pressor test. The Japanese Journal of Physiology, 42(2), 239-252. doi:10.2170/jjphysiol.42.239 